\section{International Scientific Journal Theoretical \& Applied Science}

\author{
p-ISSN: 2308-4944 (print) e-ISSN: 2409-0085 (online) \\ Year: 2015 Issue: $01 \quad$ Volume: 21 \\ Published: $30.01 .2015 \quad$ http://www.T-Science.org
}

Igor Viktorovich Balynin postgraduate student, Financial University under the Government of the Russian Federation, Russia igorbalynin@mail.ru

SECTION 31. Economic research, finance, innovation, and risk management.

\title{
DEVELOPMENT OF SMALL BUSINESS IN THE RUSSIAN FEDERATION FOR 2011-2013
}

Abstract: The article presents the results of the analysis of small businesses, excluding micro-enterprises, in the Russian Federation in 2011-2013, on four key indicators: number; average number of employees; turnover in monetary terms and in relation to GDP. The study was conducted as in the whole of the Russian Federation and by federal districts.

Key words: small entrepreneurship, small business, economic policy, regional economics, economic problems, investment, entrepreneurship.

Language: Russian

Citation: Balynin IV (2015) DEVELOPMENT OF SMALL BUSINESS IN THE RUSSIAN FEDERATION FOR 2011-2013. ISJ Theoretical \& Applied Science $01 \quad$ (21): 184-189. http://dx.doi.org/10.15863/TAS.2015.01.21.31

\section{РАЗВИТИЕ МАЛОГО ПРЕДПРИНИМАТЕЛЬСТВА В РОССИЙСКОЙ ФЕДЕРАЦИИ В 2011-2013 ГГ.}

Аннотация: В статье представлены результаты анализа деятельности мальх предприятий (без учета микропредприятий) в Российской Федерации в 2011-2013 годы по четырем ключевым показателям: количество; средняя численность работников; оборот в денежном выражении и в отношении к ВВП. Исследование проведено как в целом по Российской Федерации, так и в разрезе федеральных округов.

Ключевые слова: малое предпринимательство, мальй бизнес, экономическая политика, региональная экономика, экономические проблемы, инвестиции, предпринимательство.

Малое предпринимательство, выступая особой формой экономической активности, является ключевым звеном и индикатором развития российской экономики. В связи с этим изучение вопросов, связанных с его деятельностью, проблемами и тенденций дальнейшего развития является не только актуальным, но и необходимым.

Для оценки развития российского малого предпринимательства необходимо изучить динамику их количества, средней численности работников и оборота.

Для этого построим таблицу 1, опираясь на данные Федеральной службы государственной статистики [13] о малых предприятиях (без учета микропредприятий) и самостоятельно произведенные на их основе расчеты. Так, в первой столбце таблицы используем следующие показатели:
1) П1 - количество малых предприятий, в единицах

2) П2 - средняя численность работников, тыс. чел.

3) П3 - оборот, млрд. руб.

4) П4 - оборот, в \% к ВВП

По таблице 1 видно, что в исследуемом периоде в Российской Федерации произошло сокращение количества малых предприятий на 8532 единицы (в относительном выражении - на $3,51 \%$ ), уменьшение средней численности работников (на $0,83 \%$, что в абсолютном исчислении превышает 58 тыс. человек), увеличение оборота на $3,73 \%$ (что в денежном выражении составляет 564, 02 млрд. руб.). Однако, доля оборота в валовом внутреннем продукте значительно сократилась - с 27,85\% (в 2011 году) до 23,69\% (в 2013 году). При этом, 
Основные характеристики малого предпринимательства в Российской Федерации в 2011-2013 годах

\begin{tabular}{|c|c|c|c|c|c|c|c|c|c|}
\hline \multirow{2}{*}{ 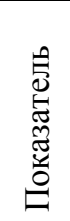 } & \multirow{2}{*}{$\begin{array}{c}2011 \\
\text { ЗП }\end{array}$} & \multicolumn{3}{|c|}{2012} & \multicolumn{5}{|c|}{2013} \\
\hline & & ЗП & $\begin{array}{c}\text { АИ } \\
\text { (к2011) }\end{array}$ & ТПС & ЗП & $\begin{array}{c}\text { АИ } \\
\text { (к 2012) }\end{array}$ & ТПС & $\begin{array}{c}\text { АИ } \\
\text { (к 2011) }\end{array}$ & $\begin{array}{l}\text { ТПС } \\
\text { (к } \\
2011)\end{array}$ \\
\hline П1 & 242677 & 243069 & +392 & $+0,16$ & 234537 & -8532 & $-3,51$ & -8140 & $-3,35$ \\
\hline П2 & 7126,02 & 6984,33 & $-141,69$ & $-1,99$ & 6926,25 & $-58,08$ & $-0,83$ & $-199,77$ & $-2,80$ \\
\hline П3 & 15584,82 & 15116,3 & $-468,52$ & $-3,01$ & 15680,32 & $+564,02$ & $+3,73$ & $+95,5$ & $+0,61$ \\
\hline$\Pi 4$ & 27,85 & 24,32 & $-3,52$ & $\mathrm{x}$ & 23,69 & $-0,63$ & $x$ & -4 & $\mathrm{x}$ \\
\hline
\end{tabular}

Условные обозначения. ЗП - значение показателя; АИ - абсолютное изменение (абсолютный прирост /снижение) $\kappa$ соответствующему году (+/-); ТПС - темп прироста / снижения (+ /-) $\kappa$ соответствуюшему году, \%.

Источник: Составлено и рассчитано автором на основании данных Федеральной службы государственной статистики [13]

Для более детального анализа состояния малого предпринимательства в Российской Федерации изучим показатели малых предприятий в разрезе федеральных округов. При этом в таблицах 2-5 использованы следующие условные обозначения: ФО - федеральный округ; ЦФО - Центральный федеральный округ; СЗФО - Северо-Западный федеральный округ; ЮФО Южный федеральный округ; СКФО - СевероКавказский федеральный округ; ПФО Приволжский федеральный округ; УФО Уральский федеральный округ; СИБФО Сибирский федеральный округ; ДФО Дальневосточный федеральный округ.

Так, соответствующие значения по П1 представлены в таблице 2.

По таблице 2 следует сделать вывод об уменьшении количества малых предприятий в 2013 году (по сравнению с 2011 годом) в Центральном федеральном округе (на 8,20\%, что в абсолютном исчислении составляет 6715 единиц), в Южном федеральном округе (на
$2,73 \%$, что в абсолютном исчислении составляет 490 единиц), в Северо-Кавказском федеральном округе (на $0,49 \%$, что в абсолютном исчислении составляет 26 единиц), в Уральском федеральном округе (на $5,52 \%$, что в абсолютном исчислении составляет 1155 единиц), в Сибирском федеральном округе (на 4,58\%, что в абсолютном исчислении составляет 1291 единицу). В то же время увеличение зафиксировано в СевероЗападном федеральном округе (на 3,44\%, что в абсолютном исчислении составляет 1082 единиц), Приволжском федеральном округе $(0,73 \%$, что в абсолютном исчислении составляет 336 единиц), Дальневосточном федеральном округе $(1,12 \%$; что в абсолютном исчислении составляет 119 единиц).

В свою очередь, результаты анализа изменений средней численности работников на малых предприятиях в Российской Федерации в разрезе федеральных округов 2011-2013 годы представлены в таблице 3 .

Количество малых предприятий в Российской Федерации в 2011-2013 гг.

Таблица 2 (в разрезе федеральных округов)

\begin{tabular}{|c|c|c|c|c|c|c|c|c|c|}
\hline \multirow[b]{2}{*}{$\Phi О$} & \multirow{2}{*}{$\begin{array}{l}2011 \\
3 \Pi\end{array}$} & \multicolumn{3}{|c|}{2012} & \multicolumn{5}{|c|}{2013} \\
\hline & & ЗП & $\begin{array}{c}\text { АИ } \\
\text { (к 2011) }\end{array}$ & ТПС & ЗП & $\begin{array}{c}\text { АИ } \\
\text { (к 2012) }\end{array}$ & ТПС & $\begin{array}{c}\text { АИ } \\
(\text { к 2011) }\end{array}$ & $\begin{array}{c}\text { ТПС } \\
\text { (к 2011) }\end{array}$ \\
\hline 1 & 2 & 3 & 4 & 5 & 6 & 7 & 8 & 9 & 10 \\
\hline ЦФО & 81936 & 76604 & -5332 & $-6,51$ & 75221 & -1383 & $-1,81$ & -6715 & $-8,20$ \\
\hline СЗФО & 31431 & 33380 & +1949 & $+6,20$ & 32513 & -867 & $-2,60$ & +1082 & $+3,44$ \\
\hline
\end{tabular}




\begin{tabular}{|c|c|c|c|c|c|c|c|c|c|}
\hline ЮФО & 17979 & 18330 & +351 & $+1,95$ & 17489 & -841 & $-4,59$ & -490 & $-2,73$ \\
\hline СКФО & 5321 & 5586 & +265 & $+4,98$ & 5295 & -291 & $-5,21$ & -26 & $-0,49$ \\
\hline ПФО & 46328 & 48351 & +2023 & $+4,37$ & 46664 & -1687 & $-3,49$ & +336 & $+0,73$ \\
\hline УФО & 20941 & 20726 & -215 & $-1,03$ & 19786 & -940 & $-4,54$ & -1155 & $-5,52$ \\
\hline СИБФО & 28158 & 29329 & +1171 & $+4,16$ & 26867 & -2462 & $-8,39$ & -1291 & $-4,58$ \\
\hline ДФО & 10583 & 10763 & +180 & $+1,70$ & 10702 & -61 & $-0,57$ & +119 & $+1,12$ \\
\hline
\end{tabular}

Условные обозначения. ЗП - значение показателя; АИ - абсолютное изменение (абсолютный прирост /снижение) $\kappa$ соответствующему году (+/-); ТПС - темп прироста / снижения (+ /-) $\kappa$ соответствующему году, \%.

Источник: Составлено и рассчитано автором на основании данных Федеральной службы государственной статистики [13].

Примечание 1. В столбияах 2-4, 6,7,9 данные представлены в единицах; в столбиах 5,8,10-в \%.

Примечание 2. В столбиах 2,3,6 приведены сведения по состоянию на 1 января года, следующего за отчетным (на 01.01.2011; 01.01.2012 и 01.01.2013 соответственно).

Анализ данных, представленных в таблице 3 позволяет сделать вывод о том, что в 2012 году по сравнению с предшествующим годом численность работников на малых предприятиях уменьшилась в Центральном федеральном округе (на $1,54 \%$, что в абсолютном исчислении составляет 33,86 тыс. чел.), в Северо-Западном федеральном округе $(3,12 \%$, что в абсолютном исчислении составляет 25,76 тыс. чел.), в Южном федеральном округе (на $8,30 \%$, что в абсолютном исчислении составляет 50,05 тыс. чел.), в Приволжском федеральном округе (на 20,26\%, что в абсолютном исчислении составляет 292,01 тыс. чел.), в Уральском федеральном округе (на $2,42 \%$, что в абсолютном исчислении составляет 15,84 тыс. чел.), в Сибирском федеральном округе (на $3,57 \%$, что в абсолютном исчислении составляет 32,33 тыс. чел.). В то же время в Дальневосточном и Северо-Кавказском федеральных округах зафиксировано увеличение численности работников на малых предприятиях - на $1,40 \%$ (что в абсолютном исчислении составляет 4,49 тыс. чел.) и на 2,03\% (что в абсолютном исчислении составляет 3,68 тыс. чел.) соответственно.

Таблица 3 Средняя численность работников на малых предприятиях в Российской Федерации в 2011-2013 годы (в разрезе федеральных округов)

\begin{tabular}{|c|c|c|c|c|c|c|c|c|c|}
\hline \multirow[b]{2}{*}{$\Phi О$} & \multirow{2}{*}{$\begin{array}{r}2011 \\
\text { ЗП }\end{array}$} & \multicolumn{3}{|c|}{2012} & \multicolumn{5}{|c|}{2013} \\
\hline & & ЗП & $\begin{array}{c}\text { АИ } \\
\text { (к 2011) }\end{array}$ & ТПС & ЗП & $\begin{array}{c}\text { АИ } \\
\text { (к 2012) }\end{array}$ & ТПС & $\begin{array}{c}\text { АИ } \\
(\kappa \\
2011)\end{array}$ & $\begin{array}{c}\text { ТПС } \\
\text { (к 2011) }\end{array}$ \\
\hline 1 & 2 & 3 & 4 & 5 & 6 & 7 & 8 & 9 & 10 \\
\hline ЦФО & 2195,26 & 2161,4 & $-33,86$ & $-1,54$ & 2172,28 & $+10,88$ & $+0,50$ & $-22,98$ & $-1,05$ \\
\hline СЗФО & 824,54 & 798,78 & $-25,76$ & $-3,12$ & 806,5 & $+7,72$ & $+0,97$ & $-18,04$ & $-2,19$ \\
\hline ЮФО & 602,66 & 552,61 & $-50,05$ & $-8,30$ & 520,39 & $-32,22$ & $-5,83$ & $-82,27$ & $-13,65$ \\
\hline СКФО & 180,93 & 184,61 & $+3,68$ & $+2,03$ & 176,39 & $-8,22$ & $-4,45$ & $-4,54$ & $-2,51$ \\
\hline ПФО & 1441,05 & 1149,04 & $-292,01$ & $-20,26$ & 1447,71 & $+298,67$ & $+25,99$ & $+6,66$ & $+0,46$ \\
\hline УФО & 654,59 & 638,75 & $-15,84$ & $-2,42$ & 623,83 & $-14,92$ & $-2,34$ & $-30,76$ & $-4,70$ \\
\hline СИБФО & 905,5 & 873,17 & $-32,33$ & $-3,57$ & 854,72 & $-18,45$ & $-2,11$ & $-50,78$ & $-5,61$ \\
\hline ДФО & 321,49 & 325,98 & $+4,49$ & $+1,40$ & 324,42 & $-1,56$ & $-0,48$ & $+2,93$ & $+0,91$ \\
\hline
\end{tabular}

Условные обозначения. ЗП - значение показателя; АИ - абсолютное изменение (абсолютный прирост /снижение) $\kappa$ соответствующему году (+/-); ТПС - темп прироста / снижения (+ /-) $\kappa$ соответствующему году, \%.

Источник: Составлено и рассчитано автором на основании данных Федеральной службь государственной статистики [13]

Примечание . В столбиах 2-4, 6,7,9 данные представлены в тыс. чел. ; в столбиах 5,8,10 - в \%. 
Более того, проведенный анализ также показал, что в 2013 году (по сравнению с 2011 годом) средняя численность работников на малых предприятиях уменьшилась в Центральном федеральном округе (на 1,05\%, что в абсолютном исчислении составляет 22,98 тыс.чел.), в СевероЗападном федеральном округе (на 2,19\%, что в абсолютном исчислении составляет 18,04 тыс. чел.), в Южном федеральном округе (на 13,65\%, что в абсолютном исчислении составляет 82,27 тыс. чел.), в Северо-Кавказском федеральном округе (на 2,51\%, что в абсолютном исчислении составляет 4,54 тыс. чел.), в Уральском федеральном округе (на $4,70 \%$, что в абсолютном исчислении составляет 30,76 тыс. чел.), в Сибирском федеральном округе (на $5,61 \%$, что в абсолютном исчислении составляет 50,78 тыс. чел.). При этом, рост средней численности работников на малых предприятиях выявлен в Приволжском и Дальневосточном федеральных округах - на $0,46 \%$ (что в абсолютном исчислении составляет 6,66 тыс. чел.) и $0,91 \%$ (что в абсолютном исчислении составляет 2,93 тыс. чел.) соответственно.

Результаты анализа оборота малых предприятий в Российской Федерации в разрезе федеральных округов в 2011-2013 годы представлены в таблице 4. Анализ данных, представленных в таблице 4, позволяет сделать вывод о том, что в Центральном и Дальневосточном федеральном округе в 2012 году (по сравнению с 2011 годом) оборот сократился на $16,51 \%$ (что в абсолютном исчислении составляет 1148,22 млрд. руб.) и $1,86 \%$ (что в абсолютном исчислении составляет 10,76 млрд. руб.) соответственно. В то же время увеличение оборота малых предприятий зафиксировано в Северо-Западном федеральном округе на 1,68\% (что в абсолютном исчислении составляет 29,19 млрд. руб.), в Южном федеральном округе на $11,88 \%$ (что в абсолютном исчислении составляет 119,07 млрд. руб.), в Северо-Кавказском федеральном округе на $10,15 \%$ (что в абсолютном исчислении составляет 27,8 млрд. руб.), в Приволжском федеральном округе на $14,86 \%$ (что в абсолютном исчислении составляет 338,93 млрд. руб.), в Уральском федеральном округе на 7,42\% (что в абсолютном исчислении составляет 98,7 млрд. руб.), в Сибирском федеральном округе на $5,37 \%$ (что в абсолютном исчислении составляет 76,75 млрд. руб.).

Оборот малых предприятий в Российской Федерации в 2011-2013 годы.

Таблица 4

\begin{tabular}{|c|l|c|c|c|c|c|c|c|c|}
\hline \multirow{2}{*}{ ФО } & 2011 & \multicolumn{3}{|c|}{2012} & \multicolumn{5}{|c|}{2013} \\
\cline { 2 - 11 } & ЗП & ЗП & $\begin{array}{c}\text { АИ } \\
\text { (к 2011) }\end{array}$ & ТПС & ЗП & $\begin{array}{c}\text { АИ } \\
\text { (к 2012) }\end{array}$ & ТПС & $\begin{array}{c}\text { АИ } \\
\text { (к } \\
2011)\end{array}$ & $\begin{array}{c}\text { ТПС } \\
\text { (к } \\
2011)\end{array}$ \\
\hline ЦФО & 6955,66 & 5807,44 & $-1148,22$ & $-16,51$ & 5952,82 & $+145,38$ & $+2,50$ & $-1002,8$ & $-14,42$ \\
\hline СЗФО & 1732,38 & 1761,57 & $+29,19$ & $+1,68$ & 1840,96 & $+79,39$ & $+4,51$ & $+108,6$ & $+6,27$ \\
\hline ЮФО & 1001,9 & 1120,97 & $+119,07$ & $+11,88$ & 1176,45 & $+55,48$ & $+4,95$ & $+174,6$ & $+17,4$ \\
\hline СКФО & 274 & 301,8 & $+27,8$ & $+10,15$ & 337,03 & $+35,23$ & $+11,7$ & $+63,03$ & $+23,0$ \\
\hline ПФО & 2280,14 & 2619,07 & $+338,93$ & $+14,86$ & 2860,09 & $+241,02$ & $+9,20$ & $+580,0$ & $+25,4$ \\
\hline УФО & 1330,96 & 1429,66 & $+98,7$ & $+7,42$ & 1414,12 & $-15,54$ & $-1,09$ & $+83,16$ & $+6,25$ \\
\hline СИБФО & 1430,17 & 1506,92 & $+76,75$ & $+5,37$ & 1486,38 & $-20,54$ & $-1,36$ & $+56,21$ & $+3,93$ \\
\hline ДФО & 579,62 & 568,86 & $-10,76$ & $-1,86$ & 612,48 & $+43,62$ & $+7,67$ & $+32,86$ & $+5,67$ \\
\hline
\end{tabular}

Условные обозначения. ЗП - значение показателя; АИ - абсолютное изменение (абсолютный прирост /снижение) $\kappa$ соответствуюшему году (+/-); ТПС - темп прироста / снижения (+ /-) $\kappa$ соответствующему году, \%.

Источник: Составлено и рассчитано автором на основании данных Федеральной службь государственной статистики [13]

Примечание. В столбцах 2-4, 6,7,9 данные представлень в млрд.руб.; в столбцах 5,8,10 - в \%.

При осуществлении сравнительного анализа данных 2013 и 2011 годов выявлено уменьшение оборота малых предприятий исключительно в Центральном федеральном округе - на 14,42\%, что в абсолютном исчислении составляет 1002,84 млрд .руб. В то же время в остальных федеральных округах выявлен рост: в СевероЗападном федеральном округе - на 6,27\% (что в абсолютном исчислении составляет 108,58 млрд. руб.); в Южном федеральном округе - на 17,42\% 
(что в абсолютном исчислении составляет 174,55 млрд. руб.); в Северо-Кавказском федеральном округе - на 23,00\% (что в абсолютном исчислении составляет 63,03 млрд. руб.); в Приволжском федеральном округе - на 25,43\% (что в абсолютном исчислении составляет 579,95 млрд. руб.); в Уральском федеральном округе на $6,25 \%$ (что в абсолютном исчислении составляет 83,16 млрд. руб.); в Сибирском федеральном округе - на $3,93 \%$ (что в абсолютном исчислении составляет 56,21 млрд. руб.); в Дальневосточном федеральном округе на $5,67 \%$ (что в абсолютном исчислении составляет 32,86 млрд. руб.).

В таблице 5 представлены результаты расчета доли оборота малых предприятий в валовом внутреннем продукте Российской Федерации (в разрезе по федеральным округам) за 2011-2013 годы.

Доля оборота малых предприятий в ВВП Российской Федерации, в \%.

Таблица 5

\begin{tabular}{|c|c|c|c|c|c|c|}
\hline \multirow[b]{2}{*}{$\Phi О$} & 2011 & \multicolumn{2}{|c|}{2012} & \multicolumn{3}{|c|}{2013} \\
\hline & ЗП & ЗП & $\begin{array}{c}\text { АИ } \\
\text { (к 2011) }\end{array}$ & ЗП & $\begin{array}{c}\text { АИ } \\
\text { (к 2012) }\end{array}$ & $\begin{array}{c}\text { АИ } \\
\text { (к 2011) }\end{array}$ \\
\hline ЦФО & 12,43 & 9,34 & $-3,08$ & 8,99 & $-0,35$ & $-3,44$ \\
\hline СЗФО & 3,10 & 2,83 & $-0,26$ & 2,78 & $-0,05$ & $-0,31$ \\
\hline ЮФО & 1,79 & 1,80 & $+0,01$ & 1,78 & $-0,03$ & $-0,01$ \\
\hline СКФО & 0,49 & 0,49 & 0,00 & 0,51 & $+0,02$ & $+0,02$ \\
\hline ПФО & 4,07 & 4,21 & $+0,14$ & 4,32 & $+0,11$ & $+0,25$ \\
\hline УФО & 2,38 & 2,30 & $-0,08$ & 2,14 & $-0,16$ & $-0,24$ \\
\hline СИБФО & 2,56 & 2,42 & $-0,13$ & 2,25 & $-0,18$ & $-0,31$ \\
\hline ДФО & 1,04 & 0,92 & $-0,12$ & 0,93 & $+0,01$ & $-0,11$ \\
\hline
\end{tabular}

Условные обозначения. ЗП - значение показателя; АИ - абсолютное изменение (абсолютный прирост /снижение) $\kappa$ соответствующему году (+/-); ТПС - темп прироста / снижения (+ /-) $\kappa$ соответствующему году, \%.

Источник: Составлено и рассчитано автором на основании данных Федеральной службь государственной статистики [13]

Анализ данных, представленных в таблице 5, показывает, что в исследуемом периоде (20112013 годы) произошло сокращение доли оборота малых предприятий в ВВП Российской Федерации в Центральном (на 3,44\%), СевероЗападном (на 0,31\%), в Южном (на 0,01\%), Уральском (на 0,24\%), Сибирском (на 0,31\%), Дальневосточном (на $0,11 \%$ ) федеральных округах. В то же время, увеличение обнаружено в Северо-Кавказском и Приволжском федеральных округах - на $0,02 \%$ и $0,25 \%$ соответственно.

Bce вышеперечисленное обусловлено наличием в настоящее время определенных проблем и преград его развития малых предприятий. Это связано с целым рядом обстоятельств. Так, например, необходимо отметить присущий российскому малому предпринимательству слабый уровень менеджмента и отсутствие желание у работников выполнять свои трудовые обязанности на высоком уровне.

Считаем обязательным обратить внимание и на роль государства в преодолении трудностей, с которым сталкиваются предприятия малого

ISPC European Science,

Linköping, Sweden бизнеса. В этом контексте, следует отметить, что органами государственной (как федерального, так и регионального уровня) и муниципальной власти следует активно проводятся различные конкурсы и мероприятия, направленные на увеличение эффективности функционирования малого предпринимательства. Так, 29 января 2015 года в Калужской области был проведен семинар-тренинг «Эффективные методы ведения конкурентной борьбы» (включающий 4 части: «кризис и конкуренция»; «типовые ошибки и потеря конкурентоспособности»; «взаимодействие с потребителями», «современные технологии коммуникации и конкуренции») [15]. Более того, в начале февраля 2015 года планируется провести «Ярмарку финансовых и кредитных услуг: программы кредитования малого и среднего бизнеса» [14].

Необходимо также подчеркнуть, что Калужская область реализует целый комплекс мер, направленных привлечение инвестиций (в т.ч. иностранных) в регион (в т.ч. и посредством реализуемой бюджетной политики), что также 
способствует развитию малого и среднего бизнеса в этом субъекте Российской Федерации.

Таким образом, проведенное исследование показало, что несмотря на созданные условия для создания малого и среднего бизнеса, существует ряд преград и препятствий, сдерживающие его развитие. Так, в исследуемом периоде в Российской Федерации произошло сокращение количества малых предприятий на 8532 единицы (в относительном выражении - на 3,51\%), уменьшение средней численности работников (на $0,83 \%$, что в абсолютном исчислении превышает 58 тыс. человек), увеличение оборота на 3,73\% (что в денежном выражении составляет 564, 02 млрд. руб.). При этом, доля оборота в валовом внутреннем продукте сократилась значительно с 27,85\% (в 2011 году) до 23,69\% (в 2013 году).

Однако, благодаря грамотной и взвешенной политике, проводимой российскими органами власти на всех ее уровнях, а также повышению качества финансового менеджмента на малых предприятиях, существующие проблемы будут решаться, имеющиеся преграды устраняться, а малый бизнес будет развиваться, становясь главным драйвером экономического роста в нашем государстве. Но для этого необходимо время и проведение целого комплекса мероприятий, а также максимальное использование имеющегося потенциала и существующих возможностей.

\section{References:}

1. (2014) Nalogovyiy kodeks Rossiyskoy Federatsii (chast vtoraya) ot 05.08.2000 N 117FZ (red. ot 29.12.2014).

2. (2014) Federalnyiy zakon ot 24.07.2009 N 212FZ (red. ot 29.12.2014) "O strahovyih vznosah V Pensionnyiy fond Rossiyskoy Federatsii, Fond sotsialnogo strahovaniya Rossiyskoy Federatsii, Federalnyiy fond obyazatelnogo meditsinskogo strahovaniya".

3. Barasheva EN (2014) Povyishenie dohodnoy bazyi mestnyih byudzhetov na osnove razvitiya malogo i srednego biznesa. Nauchnoe obozrenie. 2014. \# 8-1. pp. 338-343.

4. Bolshuhina IS (2014) Finansovyiy mehanizm gosudarstvennoy podderzhki sub'ektov malogo i srednego predprinimatelstva $\mathrm{v}$ Rossii: problemyi i perspektivyi razvitiya. Finansyi i kredit. 2014. \# 40. pp. 17-26.

5. Burlakov VV (2014) Maloe innovatsionnoe predprinimatelstvo kak faktor razvitiya sovremennoy ekonomiki. Ekonomika i predprinimatelstvo. 2014. \# 1-3. pp. 661-663.

6. Markina IA (2013) Razvitie malogo biznesa v regione: metodicheskie i prakticheskie aspektyi. Biznes. Obrazovanie. Pravo. Vestnik Volgogradskogo instituta biznesa. 2013. \# 3 (24). pp. 32-34.

7. Pinkovetskaya YS (2014) Proizvodstvennyie funktsii predprinimatelskih struktur v regionah. Audit i finansovyiy analiz. 2014. \# 2. pp. 156160.

8. Solod TV (2014) Maloe predprinimatelstvo v sisteme ekonomicheskoy bezopasnosti regiona (Rostovskaya oblast). Biznes. Obrazovanie. Pravo. Vestnik Volgogradskogo instituta biznesa. 2014. \# 1. pp. 181-184.
9. Trubnikova LS, Medvedev SA (2013) Innovatsionnoe pozitsionirovanie sub'ektov malogo predprinimatelstva $\mathrm{v}$ usloviyah modernizatsii ekonomiki. Ekonomicheskie issledovaniya. 2013. \# 4. pp. 1

10. Sergienko NS (2014) Byudzhet Kaluzhskoy oblasti $\mathrm{v}$ usloviyah realizatsii investitsionnoy politiki regiona. Ekonomicheskie, yuridicheskie i sotsiokulturnyie aspektyi razvitiya regionov. Chelyabinsk, 2014. pp. 54-57.

11. (2015) Korporativnyiy seminar-praktikum «Kak sohranit biznes posle vstupleniya Rossii v VTO». Vstuplenie Rossii v VTO. - Available: http://www.martex.ru/2938 (Accessed:25.01.15).

12. (2015) Krupneyshie banki na ryinke kreditovaniya malogo i srednego biznesa $\mathrm{V}$ 2012 godu// RBK. Reyting. - Available: http://rating.rbc.ru/article.shtml?2013/04/23/33 933473 (Accessed:25.01.15).

13. (2015) Federalnaya sluzhba gosudarstvennoy statistiki. - Available: http://www.gks.ru/ (Accessed:25.01.15).

14. (2015) Yarmarka finansovyih i kreditnyih uslug: programmyi kreditovaniya malogo i srednego biznesa - Available: http://www.pmp.admoblkaluga.ru/content/news /regional/reggeneral/m,29,19278/ (Accessed:25.01.15).

15. (2015) Seminar-trening «Effektivnyie metodyi vedeniya konkurentnoy borbyi» - Available: http://www.pmp.admoblkaluga.ru/content/news /regional/reggeneral/m,29,19276/

(Accessed:25.01.15). 